\title{
Assessment of the Levels of Cardiovascular Risk Markers in Hyperglycemic Young Nigerian Adults
}

\author{
Anthony C. Nnamudi, Noghayin E. J. Orhue, and Ifeoma I. Ijeh
}

\section{ABSTRACT}

Background: The burden of cardiovascular diseases in developing countries such as Nigeria is worsened by the increasing prevalence of cardiovascular risk factors. This study is aimed at assessing the levels of cardiovascular risk markers in young Nigerian adults who are hyperglycemic at baseline.

Material and Methods: A total of 200 participants (male and female), aged 15-35 years initially took part in the study while the data of 61 participants (44.3\% male and $\mathbf{5 5 . 7 \%}$ female) who were hyperglycemic at baseline was analyzed using Statistical Package for the Social Sciences (SPSS) version 23.0. The levels of cardiovascular risk markers were analyzed in these hyperglycemic young adults.

Results: The females in the study population had a higher blood glucose level $(102.91 \pm 9.68)$ when compared to males $(98.81 \pm 8.13)$. The study reported the prevalence rates for cardiovascular risk markers: hypertension [31.15\% (male), 14.70\% (female)]; overweight and obesity [33.33\% (males), $52.94 \%$ (females)]; central obesity [14.81\% (males), $64.70 \%$ (females)]; high waist-to-hip ratio $[33.33 \%$ (males), $91.18 \%$ (females)]; hypercholesterolemia and low LDL-C [37.04\% and 33.33\% respectively (males), $67.65 \%$ and $61.76 \%$ respectively (females)]; hypertriglyceridemia $[25.92 \%$ (males), $\mathbf{1 7 . 6 0 \%}$ (females)]; high atherogenic index of plasma $[25.92 \%$ (males), $14.70 \%$ (females)]; elevated C-reactive protein $[\mathbf{7 . 4 1 \%}$ (males), $\mathbf{8 . 8 2 \%}$ (females)]. The cardiovascular risk markers were more prevalent in females relative to the males.

Conclusions: The high prevalence of cardiovascular risk markers suggests that most apparently healthy Nigerians, including young adults may be at high risk of developing cardiovascular diseases.

Keywords: body mass index, cardiovascular diseases, hyperglycemia, young adults.

\section{INTRODUCTION}

Diabetes and other factors such as hypertension and particularly dyslipidaemia are perhaps among the most severe cardiovascular risk determinants. Dyslipidaemia is a common phenomenon in patients with type 2 diabetes mellitus or metabolic syndrome. In cardiovascular patients, it is mainly characterized by elevated levels of total cholesterol and low density lipoprotein-cholesterol while elevated triglycerides and lower high density lipoproteincholesterol are found 2 and 1.5 times more frequently, respectively. The risk of cardiovascular diseases is increased by diabetes mellitus via increased triglyceride levels, low levels of high density lipoprotein-cholesterol and postprandial lipidaemia [1]-[3].

Hyperglycemia contributes to cardiovascular complications in patients with type 2 diabetes [4]. This, in addition to other findings provide convincing evidences strongly supporting the causal relationship between
Published Online: June 20, 2020

ISSN: $2684-5199$

DOI : $10.24018 /$ ejbio.2020.1.3.22

\section{A. C. Nnamudi*}

Department of Biochemistry, Faculty of Basic Medical Sciences, PAMO University of Medical Sciences, Port Harcourt, Nigeria.

(anthonynnamudi@gmail.com;

annamudi@pums.edu.ng)

\section{N. E. J. Orhue}

Department of Biochemistry, Faculty of Life Sciences, University of Benin, Benin City, Nigeria

(noghayin.orhue@uniben.edu)

\section{I. Ijeh}

Department of Biochemistry, Faculty of Basic Medical Sciences, PAMO University of Medical Sciences, Port Harcourt, Nigeria.

(iijeh@pums.edu.ng)

*Corresponding Author hyperglycemia and cardiovascular disease. It is equally well established that cardiovascular disease is a common complication of diabetes mellitus and a leading cause of death among people with diabetes [5]. It therefore suffices to state that, hyperglycemia lies at the cross roads of diabetes mellitus and its complications as well as the development of cardiovascular diseases.

Cardiovascular disease, including stroke, heart failure and kidney disease is common in sub-Saharan Africa as increasing cases of ischaemic heart disease and metabolic disorders can be traced to rapid urbanization [6]. Also, the burden of cardiovascular diseases in developing countries such as Nigeria is worsened by the increasing prevalence of risk factors for cardiovascular diseases [7].

Whereas nine modifiable traditional risk factors (including smoking, history of hypertension or diabetes, obesity, unhealthy diet, lack of physical activity, excessive alcohol consumption, raised blood lipids and psychosocial factors) are responsible for most of the population risk of 
cardiovascular diseases, eight of them (excessive alcohol consumption, tobacco use, high blood pressure, high body mass index (BMI), high cholesterol, high blood glucose, dietary choices and physical inactivity) account for $61 \%$ of deaths resulting from cardiovascular diseases globally [8], [6].

In 2008, cardiovascular diseases and diabetes were jointly responsible for an estimated mortality of 435.9/100,000 and 475.7/100,000 for males and females, respectively in Nigeria. Despite the lack of a mechanism for communitywide data collection on non-communicable diseases in Nigeria, the country has an estimated proportional mortality rate of $12 \%$ attributable to cardiovascular diseases [9], [10]. It is therefore a considered view that the actual mortality rate may be higher.

Available evidence clearly indicate an early onset of disease burden yet risk screening for cardiovascular diseases is still at sub-optimal level in Nigeria [11], [3]. Although an earlier study reported a low incidence of stroke in young Nigerian adults, it however suggested the need to reduce the impact of stroke on the young adults by focusing on the preventable or modifiable risk factors especially hypertension, being the most common risk factor [11].

Approximately 1 billion people had uncontrolled hypertension worldwide in 2008 [12] with the highest prevalence rate of $46 \%$ in Africa. The prevalence of cardiovascular disease and hypertension is rapidly increasing in sub-Saharan Africa [13]. Sadly, sub-Saharan Africa, the prevention, detection, treatment and control of hypertension is at sub-optimal level and haphazard [6]. This is worrying as an increase in hypertension prevalence will correspond to an increase in the prevalence of cardiovascular diseases since it is perhaps the most common risk factor.

Certain biomarkers when assayed alone or in combination with others can play significant roles in cardiovascular risk prediction as well as the determination of the status of morbidity of cardiovascular diseases. The measurement of a standard lipid profile including total cholesterol, low density lipoprotein-cholesterol, high density lipoprotein-cholesterol and triglycerides is recommended in establishing the risk status of cardiovascular diseases [2].

A gradual reduction in the prevalence of infectious diseases and an increase in the prevalence of noncommunicable diseases suggests the possibility of an epidemiological transition, thus implying that efforts should be targeted at halting the surge of non-communicable diseases, especially cardiovascular diseases.

This study is therefore aimed at assessing the levels of cardiovascular risk markers in young Nigerian adults who are hyperglycemic at baseline.

\section{MATERIALS AND METHODS}

This study was carried out in Asaba, the capital city of Delta state, in the South-South region of Nigeria between June and December, 2019.

\section{A. Recruitment of Participants}

Male and female participants, aged 15-35 years, were recruited by convenience sampling without any form of bias. The study was explained to them to a reasonable extent. Prior to participating, the participants had to fill the informed consent form which was designed in line with the guidelines of the research ethics review committee of World Health Organization. Their fasting blood sugar level was measured to confirm their hyperglycemic status at baseline.

\section{B. Ethical Approval}

The Ministry of Health Research Ethics Committee (MOHREC) of Delta State, Nigeria approved the study protocol (HM/596/T/55).

\section{Inclusion/Exclusion Criteria}

Participants were included in the study if they were hyperglycemic at baseline (fasting blood glucose > 90 $\mathrm{mg} / \mathrm{dL}$ but not exceeding $125 \mathrm{mg} / \mathrm{dL}$ ). Participants shall be excluded from the study: if they have been previously diagnosed of diabetes, if they are currently using prescribed drugs for the control and management of diabetes, if they are known hypertensive, if they are currently using antihypertensive drugs, if they decline to offer consent of participation.

\section{Anthropometric Measurements}

Weight was measured using a weighing scale, with participant dressed in light clothing. Height was measured using a stadiometer. Thereafter, body mass index (BMI) was calculated by dividing the weight (in kilograms) by the square of the height (in metres). Waist circumference and hip circumference were measured (in centimetres) with the participant in an erect posture and waist-to-hip ratio was determined. The blood pressure measurement was taken by a trained personnel, while the participant remained in a sitting position. The systolic blood pressure (SBP) and diastolic blood pressure (DBP) were recorded at the 1st and 5th Korotkoff sounds, respectively. Two separate measurements were taken per participant and the average reading was eventually recorded.

\section{E. Biochemical Analysis}

All participants had an overnight fast of 10-12 hours before the study. The baseline fasting blood sugar of participants was determined using a standard glucometer. Thereafter, for participants whose fasting blood sugar was within the defined reference range of hyperglycemia, whole blood $(5 \mathrm{~mL})$ was then withdrawn and collected in EDTA (ethylenediamine tetraacetic acid) containing bottle. The plasma was separated by centrifugation. The concentration of total cholesterol, HDL-cholesterol and triglycerides were determined by enzymatic colorimetric methods [14]-[16] LDL-cholesterol was determined by the Friedewald equation [17]. Atherogenic index of plasma (AIP) was determined by calculation [18]. Glycated hemoglobin was measured using immunoturbidimetric method. C-reactive protein was analyzed using enzyme-linked immunosorbent assay (ELISA) technique.

\section{F. Risk Definition}

The cardiovascular risk definition used in this study was similar to the definition of risk factors adopted by Sani et al., [19] although with some modifications. Hypertension 
was defined by blood pressure $(>130 / 85 \mathrm{mmHg})$ based on the current 2017 ACC/AHA guidelines [20]. Hyperglycemia was defined by a fasting blood glucose $>90$ $\mathrm{mg} / \mathrm{dL}$ but not exceeding $125 \mathrm{mg} / \mathrm{dL}$. Total cholesterol, LDL-cholesterol, triglycerides were defined as high if the levels were $\geq 240 \mathrm{mg} / \mathrm{dL},>130 \mathrm{mg} / \mathrm{dL}$ and $>150 \mathrm{mg} / \mathrm{dL}$ respectively while HDL-cholesterol was defined as low if the level was $<40 \mathrm{mg} / \mathrm{dL}$ in men and $<50 \mathrm{mg} / \mathrm{dL}$ in women. BMI was defined by the WHO classification [21]. Atherogenic index of plasma, c-reactive protein and glycated hemoglobin were defined as high risk if values were $>0.21,>3$ and $>5.7$ respectively.

\section{G. Statistical Analysis}

All statistical analysis was done using the Statistical Package for the Social Sciences (SPSS) version 23.0.

\section{RESULTS}

A total of 200 participants, aged 15-35 years, were initially recruited for the study, with 61 participants having presented with hyperglycemia at baseline which represents a hyperglycemic rate of $30.5 \%$ in the study population. Amongst these 61 hyperglycemic young adults, there were 27 males $(44.3 \%)$ and 34 females $(55.7 \%)$ representing a ratio of $1: 1.26$.

The age and sex distribution of the hyperglycemic participants are shown in Fig. 1.

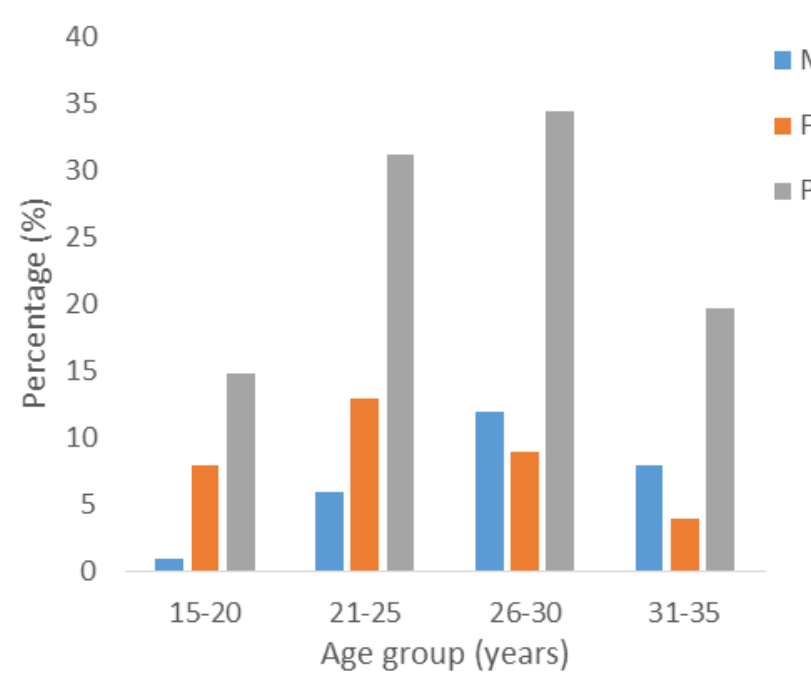

Fig. 1. Age and sex distribution of study participants.

Most of the study participants $(34.4 \%)$ were in the $26-30$ age group. The values (mean \pm SD) of anthropometric and biochemical parameters are presented in table 1 . The study participants had a fasting blood glucose of $102.10 \pm 9.19$. The females had a higher blood glucose level (102.91 \pm 9.68) when compared to the males $(98.81 \pm 8.13)$. The overall and gender frequency distribution of risk markers are presented in table 2 . There were $19(31.15 \%)$ male and 5 $(14.70 \%)$ female participants who had hypertension, giving a total of $19(31.15 \%)$ participants with hypertension. Overweight and obesity was observed in more females $(52.94 \%)$ than males $(33.33 \%)$ as was central obesity $(64.70 \%$ in females and $14.81 \%$ in males). A large percentage of the females $(91.18 \%)$ had high waist-to-hip ratios relative to the males $(33.33 \%)$. Although hypercholesterolemia and low LDL-C were found in more females $(67.65 \%$ and $61.76 \%$ respectively) than males (37.04\% and $33.33 \%$ respectively), hypertriglyceridemia was observed in $25.92 \%$ males and $17.6 \%$ females. More males $(25.92 \%)$ had high atherogenic index of plasma (AIP) than females $(14.70 \%)$. Elevated CRP levels were found in more females $(8.82 \%)$ than males $(7.41 \%)$.

TABLE 1: MEANS OF ANTHROPOMETRIC AND BIOCHEMICAL PARAMETERS

\begin{tabular}{cccc}
\multicolumn{4}{c}{ TABLE 1: MEANS OF ANTHROPOMETRIC AND BIOCHEMICAL PARAMETERS } \\
\hline Parameter & Total $(\mathrm{n}=61)$ & Male $(\mathrm{n}=27)$ & Female $(\mathrm{n}=34)$ \\
\hline FBS $(\mathrm{mg} / \mathrm{dL})$ & $101.10 \pm 9.19$ & $98.81 \pm 8.13$ & $102.91 \pm 9.68$ \\
BMI $\left(\mathrm{kg} / \mathrm{m}^{2}\right)$ & $24.64 \pm 3.88$ & $24.21 \pm 3.91$ & $25.18 \pm 3.85$ \\
Systolic BP $(\mathrm{mmHg})$ & $124.31 \pm 16.44$ & $133.96 \pm 15.87$ & $116.65 \pm 12.50$ \\
Diastolic BP $(\mathrm{mmHg})$ & $77.23 \pm 9.81$ & $80.30 \pm 10.94$ & $74.79 \pm 8.17$ \\
WC $(\mathrm{cm})$ & $84.57 \pm 9.42$ & $85.07 \pm 9.49$ & $84.18 \pm 9.49$ \\
WHR & $0.87 \pm 0.05$ & $0.86 \pm 0.05$ & $0.87 \pm 0.05$ \\
Cholesterol $(\mathrm{mg} / \mathrm{dL})$ & $251.31 \pm 47.88$ & $241.23 \pm 45.49$ & $259.31 \pm 48.87$ \\
Triglycerides $(\mathrm{mg} / \mathrm{dL})$ & $113.30 \pm 41.46$ & $116.87 \pm 47.63$ & $110.46 \pm 36.32$ \\
HDL-C $(\mathrm{mg} / \mathrm{dL})$ & $93.60 \pm 27.83$ & $91.75 \pm 35.35$ & $95.08 \pm 20.45$ \\
LDL-C $(\mathrm{mg} / \mathrm{dL})$ & $135.04 \pm 54.92$ & $126.11 \pm 54.37$ & $142.13 \pm 55.12$ \\
AIP & $0.076 \pm 0.024$ & $0.105 \pm 0.041$ & $0.053 \pm 0.028$ \\
CRP $(\mathrm{mg} / \mathrm{dL})$ & $2.72 \pm 0.36$ & $2.81 \pm 0.58$ & $2.65 \pm 0.46$ \\
HbA1c $(\%)$ & $3.89 \pm 0.88$ & $4.17 \pm 0.84$ & $3.67 \pm 0.86$ \\
\hline
\end{tabular}

Values are expressed as Mean $\pm \mathrm{SD}$

$\mathrm{FBS}=$ Fasting Blood Sugar; BMI = Body Mass Index; $\mathrm{BP}=$ Blood Pressure; WC = Waist Circumference; WHR = Waist-to-Hip Ratio; HDL$\mathrm{C}=$ High Density Lipoprotein-Cholesterol; LDL-C = Low Density Lipoprotein-Cholesterol; AIP = Atherogenic Index of Plasma; CRP = Creactive Protein; HbA1c $=$ Glycated Hemoglobin.

TABLE 2: FREQUENCY DISTRIBUTION OF RISK MARKERS

\begin{tabular}{cccc}
\hline Risk Marker & Total, n (\%) & Male, $\mathrm{n}(\%)$ & $\begin{array}{c}\text { Female, } \mathrm{n} \\
(\%)\end{array}$ \\
\hline Hypertension & $19(31.15)$ & $14(51.85)$ & $5(14.70)$ \\
Overweight and obesity & $25(40.98)$ & $9(33.33)$ & $18(52.94)$ \\
Central obesity & $26(42.62)$ & $4(14.81)$ & $22(64.70)$ \\
WHR & $40(65.57)$ & $9(33.33)$ & $31(91.18)$ \\
Hypercholesterolemia & $33(54.10)$ & $10(37.04)$ & $23(67.65)$ \\
Hypertriglyceridemia & $13(21.31)$ & $7(25.92)$ & $6(17.60)$ \\
Elevated LDL-C & $30(49.18)$ & $9(33.33)$ & $21(61.76)$ \\
CRP & $5(8.20)$ & $2(7.41)$ & $3(8.82)$ \\
AIP & $12(19.67)$ & $7(25.92)$ & $5(14.70)$ \\
\hline
\end{tabular}

\section{DISCUSSION}

On the global front, cardiovascular diseases including coronary heart disease, stroke, rheumatic heart disease, cardiomyopathy and other heart disease represent the leading cause of death [22]. The prevalence rate of cardiovascular diseases in developing nations is increasing and this is largely due to the increasing prevalence of cardiovascular risk factors and a relative lack of access to interventions that were successful in developed nations [19], [7]. This increasing prevalence provides the basis for the prediction of cardiovascular diseases to be the major causes of morbidity and mortality in most developing nations of the world by 2020 [22]. Clearly, the burden is greatly borne by low- and middle-income countries of the world where at least two-thirds of cardiovascular disease-related deaths now occur. This potentially creates a noxious dilemma of double burden of diseases resulting from infectious and cardiovascular diseases for these nations [19], [6]. Addressing the increasing burden of cardiovascular diseases has been largely ineffective in developing nations due to challenging factors such as low health care budgeting, education and skill mix of the health workforce in these countries [22]. Whereas it was previously thought of as a 
disease of the rich and developed nations of the world, there appear to be an unfortunate shift in prevalence and morbidity with increasing cardiovascular disease related deaths in the developing nations of the world, including Nigeria.

Previous studies in Nigeria have emphasized on the prevalence of risk factors with respect to specific disease conditions (such as diabetes, stroke) and have mostly been focused on adults generally [11], [19], [7], [3]. This present study attempts to assess the levels of cardiovascular risk markers in apparently healthy but hyperglycemic young Nigerian adults who are otherwise presumed to be outside the at-risk age of onset of cardiovascular diseases.

Hypertension, in addition to being the most important risk factor for cardiovascular diseases is also a major contributor to the global burden of disease [23]. The American College of Cardiology (ACC) and the American Heart Association (AHA) released the 2017 ACC/AHA guidelines for the detection and management of hypertension which recommends the use of lower systolic and diastolic blood pressure (BP) values (systolic BP $\geq 130$ $\mathrm{mmHg}$ or $\geq 80 \mathrm{mmHg}$ ) to define hypertension [20]. This study which was based on this guideline reported a $31.15 \%$ prevalence rate of hypertension among the participants as well as a higher prevalence in males $(51.85 \%)$ relative to females $(14.70 \%)$. One of the few available studies on hypertension in young adults reported a $30.6 \%$ prevalence rate of hypertension [24]. Whereas a recent study based on the same ACC/AHA 2017 guidelines reported a 55\% hypertension prevalence rate in Nigeria [23], another study based on 140/90 $\mathrm{mmHg}$ diagnostic criteria reported a $42 \%$ hypertension prevalence rate with more males relative to females being hypertensive [25]. A meta-analysis study had also reported a $28.9 \%$ overall prevalence with more males $(29.5 \%)$ relative to females $(25.0 \%)$ being hypertensive [26]. The higher prevalence in males relative to females is common in Nigerian studies. Possible reasons for the higher prevalence of hypertension in males may be the socioeconomic burden of provision of most of the financial resources for their families [27] as well as the enormous societal expectations of masculinity. Another common feature in most of these studies is a decrease in prevalence rate when the $\mathrm{BP}$ cut-off values are increased. Wide variations in prevalence rates usually arise when different blood pressure criteria are used [28]. This pattern is consistent with the results of this study. It is significant to note that these young adults were previously unaware of their hypertensive status as most of them had never taken a blood pressure measurement in the past.

The developing countries are grappling with increasing trends in overweight and obesity which are major health concerns as they significantly contribute to morbidity and mortality rates [29]. This phenomenon is not strictly an adult syndrome as it occurs significantly in children and young adults. If obesity in children and young adults is not controlled, it poses imminent risk for the onset of cardiovascular diseases, especially in developing countries where secondary prevention is poor [30]. The use of BMI measurements is widely accepted in determining overweight and obesity. This study reported slightly higher BMI values in females $(25.18 \pm 3.85)$ than males $(24.21 \pm 3.91)$ in addition to a higher prevalence of overweight or obesity $(\mathrm{BMI} \geq 25 \mathrm{~kg} / \mathrm{m} 2)$ in females $(52.94 \%)$ relative to males $(33.33 \%)$. The overall prevalence of overweight or obesity in the study population was $40.98 \%$. The results of this study are comparable to previous findings such as a $14.8 \%$ and $1.3 \%$ respective prevalence rates of overweight and obesity, which has been reported in a young adult Nigerian population [31]. Similarly, a study involving young adults in Uganda, reported a prevalence rate of $10.4 \%$ and $2.3 \%$ prevalence rate for overweight and obesity, respectively [30]. Other Nigerian studies reported $20.3 \%-35.1 \%$ rate of overweight; $8.1 \%-22.2 \%$ rate of obesity [29] and $64 \%$ overall prevalence rate of overweight or obesity [32]. This clearly points out that there is a heavy burden of overweight or obesity which is likely to worsen with increasing urbanization. There is an observed regular pattern as females had a higher prevalence rate of overweight and obesity in all of the studies. Whereas a disposition towards sedentary lifestyles may be responsible for the overall prevalence rate among the study participants, the gender disparity may be due to gender differences in metabolism and hormonal balance [33], [34], [30] and the fact that, weight gain especially amongst women is still encouraged in most Nigerian cultures [19]. Additionally, a lack of physical exercise, a tendency to be involved in less strenuous and physically demanding tasks and even inactive participation in sports due to cultural limitations may account for the higher prevalence rates of overweight and obesity in females.

Waist circumference measurement can provide an important additional information such as a measure of fat distribution which cannot be deduced from the BMI since it is used as a surrogate marker of abdominal fat mass [35]. Intra-abdominal fat is perhaps the most clinically relevant type of fat in humans [36]. It is associated with the risk of cardiovascular diseases. Thus, larger waist circumference can be used to identify people at increased risk of cardiovascular diseases [37]. Different waist circumference cut-off values are recommended for use across gender [38]. These cut-off values significantly differ between countries and the choice of cut-off value is usually based on the particular disease condition or risk [39]. The results of this study show that males $(85.07 \pm 9.49)$ had a slightly higher waist circumference than females $(84.18 \pm 9.49)$ although more of the females $(64.70 \%)$ relative to males $(14.81 \%)$ attained the threshold values $(>94 \mathrm{~cm}$ in males, $>88 \mathrm{~cm}$ in females) adopted in this study. This higher prevalence pattern in females is not uncommon in Nigerian populations [40], [41]. The risk of cardiovascular diseases increases with increasing waist circumference and the risk level proportionally increases with age [42]. The implication is that the female participants of this study may face a higher risk of developing cardiovascular diseases as they get older. Although, both male and female participants had comparable waist-to-hip ratio values $(0.86 \pm 0.05$ and 0.87 \pm 0.05 respectively), more females $(91.18 \%)$ relative to males $(33.33 \%)$ attained the cut-off points $(>0.9$ for males, $>0.8$ for females). Waist-to-hip ratio was more strongly associated with the risk of myocardial infarction (MI) than BMI. A higher waist circumference and waist-to-hip ratio is associated with a high risk of MI with women more likely 
than men to be affected [43]. This implies that if there are no interventions, the females in this study population may be at increased risk of having heart attack.

Dyslipidemia is highly prevalent in Nigeria and is a major risk factor for cardiovascular diseases [44]. This study reported a high prevalence of dyslipidemia with elevated levels of LDL-C in the overall population being the most common form. This study reports a higher prevalence of dyslipidemia in females which is in agreement with the results of previous studies [45], [19]. There is however a discrepancy with other studies since a consistent pattern of higher total cholesterol, reduced HDL-C, high LDL-C has been previously reported [45], [19], [44]. The mixed observation of high LDL-C and high triglycerides in this study indicates dyslipidemia. Surprisingly, HDL-C levels were not low enough to be considered at-risk in both sexes. Therefore, it may stand to reason that hypercholesterolemia $(54.10 \%)$ resulting mainly from elevated LDL-C (49.18\%) may be remotely responsible for the observed dyslipidemia in this study. Elevated LDL-C is strongly associated with coronary heart disease [46]. This study therefore suggests that participants, particularly the females may be at risk of coronary heart disease.

Atherogenic index of plasma (AIP) can serve as a diagnostic alternative for the prediction of cardiovascular diseases if the other measures of lipid profile [47]. It is a strong marker for predicting atherosclerosis and coronary heart disease [48] as well as coronary artery disease in postmenopausal women [49]. It has been suggested that AIP values greater than 0.24 may be associated with high risk of cardiovascular diseases [18] Apart from the atherogenic index of plasma in males $(0.105 \pm 0.041)$, the values of atherogenic index in the study population $(0.076 \pm 0.024)$ and females $(0.053 \pm 0.028)$ were lower than the recommended high risk value of 0.24 . Also, the overall high risk prevalence of $19.67 \%$ reported in this study was higher than the $16.4 \%$ reported in a Malaysian population [50]. This is not unexpected as AIP positively correlates with dyslipidemia [48] and other factors such as BMI, glucose, visceral fat, systolic and diastolic blood pressure [50]. AIP has been implicated as a surrogate for small dense low density lipoprotein (sdLDL) particles and negatively associated with the diameter of LDL-C particle. Therefore, AIP in addition to indicating a decrease in the LDL particle diameter and an increase in the proportion of sdLDL, can also be used in evaluating the risk of developing atherosclerosis [51], [49].

Glycated hemoglobin may be better than fasting glucose in macrovascular risk stratification on a long term basis. Cardiovascular risk increases as glycated hemoglobin level increases in the non-diabetic range [52], [53]. The level of glycated hemoglobin in this study $(3.89 \pm 0.88)$ was slightly higher in males $(4.17 \pm 0.84)$ relative to females $(3.67 \pm$ 0.86). However, these levels were not considered at-risk in this study as the levels were lower than the recommended high risk value of $5.7 \%-6.4 \%$. It has been suggested that glycated hemoglobin values exceeding $6.0 \%$ may be clinically useful as a diagnostic tool for the identification of individuals at risk for the development of diabetes, cardiovascular disease and death [53]. The evidence for the positive association of glycated hemoglobin with cardiovascular disease is largely observational. Although HbA1c may likely cause cardiovascular diseases, the underlying mechanisms remain unclear [54]. A recent report suggests that the abnormal levels of other conventional cardiovascular disease risk factors are mainly responsible for cardiovascular disease risk in prediabetes because $\mathrm{HbA1c}$ contributes minimally to the prediction of cardiovascular risk [55].

C-reactive protein (CRP) is a major inflammatory cytokine whose activity is stimulated by other cytokines. It is a powerful activator of the classic complement system and is also strongly linked with atherothrombosis [56]. The American Heart Association and Centers for Disease Control and Prevention recommended the use of c-reactive protein as a biomarker of inflammation and cardiovascular risk [57], [58]. A recent study reported the association of high sensitivity c-reactive protein with increased risk of developing cardiovascular disease [59]. This study reported a c-reactive protein value of $(2.72 \pm 0.36)$ while $8.20 \%$ of the study participants had elevated c-reactive protein levels although a c-reactive protein value of $(2.72 \pm 0.36)$ was reported. This value is lower than the $>3 \mathrm{mg} / \mathrm{dL}$ corresponding to high risk for future cardiovascular diseases [60]. A previous Nigerian study amongst chronic kidney disease patients reported a $20 \%$ prevalence of high risk based on CRP values [61]. Complications arising from chronic kidney disease may account for the higher risk prevalence. Data on c-reactive protein levels in young Nigerian adults are quite scarce. It has been suggested that c-reactive protein levels may only be useful in risk estimation in individuals who are already at intermediate risk for vascular events [58]. This status of vascular event could not be ascertained from our research protocol.

This study is limited by the small study size. Recruitment of participants is usually a herculean task owing to poor health awareness and poor attitude of young adults to health testing. The study size was further reduced by the elimination of normoglycemic participants. The location of the study is urban. Care should be taken in the interpretation of the results of this study for a general Nigerian population. Measurements were taken on a single occasion. This may create some measure of variation as some parameters may change over a period of time. In addition to sampling without bias, a major strength of this study is the sampling of apparently healthy young adults who had no chronic health complications.

\section{CONCLUSION}

This study clearly demonstrates that there is a high prevalence of cardiovascular risk markers among hyperglycemic young Nigerian adults. These markers are higher amongst the females relative to the males in the study population. This high prevalence of cardiovascular risk markers suggests that most apparently healthy Nigerians, including young adults may be at high risk of developing cardiovascular diseases. This therefore underscore the need for urgent public health actions to prevent cardiovascular diseases from attaining epidemic status especially among young adults. More so, regular health screening, public health awareness and sensitization 
on cardiovascular diseases and risk markers to be conducted among the general population is strongly recommended. This will ultimately reduce the burden of these risk markers.

\section{ACKNOWLEDGMENT}

This study was supported by a Federal Government of Nigeria postgraduate scholarship (FSBA/FGSS/18/PG/015) awarded to Anthony C. Nnamudi.

The authors are grateful to Vincent Onyeche, Ifeoma Onyeche and Elizabeth Ibegbulem for their invaluable assistance. The authors are equally grateful to all the young adults who participated in this study.

\section{REFERENCES}

[1] M. Jaiswal, A. Schinske, and R. Pop-Busui. "Lipids and lipid management in diabetes," Best Pract Res. Clin. Endocrinol. Metab., vol. 28, pp. 325-338, 2014.

[2] R. K. Upadhyay, "Emerging Risk Biomarkers in Cardiovascular Diseases and Disorders," J. Lipids, 971453, 2015.

[3] V. M. Oguoma, E. U. Nwose, I. I. Ulasi, A. A. Akintunde, E. E. Chukwukelu, P. T. Bwititi, et al. "Cardiovascular disease risk factors in a Nigerian population with impaired fasting blood glucose level and diabetes mellitus," BMC Public Health, vol. 17: 36, 2017.

[4] M. Laakso, "Hyperglycemia and Cardiovascular disease in type 2 diabetes," Diabetes, vol. 48, pp. 937-942, 1999.

[5] J. A. Davidson, and C. G. Parkin, "Is Hyperglycemia a Causal Factor in Cardiovascular Disease? Does proving this relationship really matter? Yes," Diabetes Care, vol. 32, pp. 331-333, 2009.

[6] F. P. Cappuccio, and M. A. Miller, "Cardiovascular disease and hypertension in sub-Saharan Africa: burden, risk and interventions," Intern Emerg Med., vol. 11, pp. 299-305, 2016.

[7] V. M. Oguoma, E. U. Nwose, T. C. Skinner, K. A. Digban, I. C. Onyia, and R. S. Richards, "Prevalence of cardiovascular disease risk factors among a Nigerian adult population: relationship with income level and accessibility to CVD risks screening," BMC Public Health, vol. 15: 397, 2015.

[8] B. J. Gersh, K. Sliwa, B. M. Mayosi, and S. Yusuf, "Novel therapeutic concepts: the epidemic of cardiovascular disease in the developing world: global implications," Eur. Heart J., vol. 31, pp. 642-648, 2010.

[9] World Health Organization, "Global Health Observatory, Noncommunicable diseases country profile. Nigeria," 2010.

[10] M. B. Maiyaki, and M. A. Garbati, "The burden of noncommunicable diseases in Nigeria; in the context of globalization," Ann. Afr. Med., vol. 13, pp. 1-10, 2014.

[11] A. C. Onwuchekwa, R. C. Onwuchekwa, and E. G. Asekomeh, "Stroke in young Nigerian adults," J. Vasc. Nurs., vol. 27, pp. 98$102,2009$.

[12] World Health Organization. "A global brief on hypertension: Silent killer, global public health crisis," Geneva: World Health Organization, 2013.

[13] Y. K. Seedat, "Recommendations for hypertension in sub-Saharan Africa," Cardiovasc. J. S. Afr., vol. 15, pp. 157-158, 2004.

[14] C. C. Allain, L. S. Poon, C. S. C. Chan, W. Richmond, and P. C. Fu, "Enzymatic colorimetric method for cholesterol estimation," Clin. Chem., vol. 20, pp. 470-475, 1974.

[15] M. F. Lopes-Virella, P. Stone, and S. Ellis, "Cholesterol determination in high density lipoprotein separated by three different methods," Clin. Chem., vol. 23: 882, 1977.

[16] N. W. Tietz, Clinical guide to laboratory tests, 2nd ed. Philadelphia, USA: WB Saunders Company, 1990, pp. 554-556.

[17] W. T. Friedewald, R. I. Levy, and D. S. Fredickson, "Estimation of the concentration of LDL cholesterol in plasma, without use of the preparative ultracentrifuge," Clin. Chem., vol. 18, pp. 499-502, 1972.

[18] M. Dobiásová, and J. Frohlich, "The plasma parameter log (TG/HDL-C) as an atherogenic index: correlation with lipoprotein particle size and esterification rate in apoB-lipoprotein-depleted plasma (FER(HDL))," Clin. Biochem., vol. 34, pp. 583-588, 2001.

[19] M. U. Sani, K. W. Wahab, B. O. Yusuf, M. Gbadamosi, O. V. Johnson, and A. Gbadamosi, "Modifiable cardiovascular risk factors among apparently healthy adult Nigerian population - a cross sectional study," BMC Res. Notes, vol. 3: 11, 2010.

[20] P. K. Whelton, R. M. Carey, W. S. Aronow, D. E. Casey, K. J. Collins, H. C. Dennison, et al. "2017 ACC/AHA/AAPA/ABC/ACPM/AGS/APhA/ASH/ASPC/NMA/PC NA Guideline for the Prevention, Detection, Evaluation, and Management of High Blood Pressure in Adults: Executive Summary: A Report of the American College of Cardiology/American Heart Association Task Force on Clinical Practice Guidelines," J. Am. Coll. Cardiol., vol. 71, pp. 2199-2269, 2018.

[21] World Health Organization. "Physical status: the use and interpretation of anthropometry. Report of a WHO expert committee," WHO Tech. Rep. Ser., vol. 854, pp. 1-452, 1995.

[22] D. S. Celermajer, C. K. Chow, E. Marijon, N. M. Anstey, and K. S. Woo, "Cardiovascular Disease in the Developing World: Prevalences, Patterns, and the Potential of Early Disease Detection," J. Am. Coll. Cardiol., vol. 60, pp. 1207-1216, 2012.

[23] N. U. Okubadejo, O. B. Ozoh, O. O. Ojo, A. O. Akinkugbe, I. A Odeniyi, O. Adegoke, et al. "Prevalence of hypertension and blood pressure profile amongst urban-dwelling adults in Nigeria: a comparative analysis based on recent guideline recommendations," Clin. Hypertens., vol. 25: 7, 2019. https://doi.org/10.1186/s40885019-0112-1.

[24] R. I. Ekore, I. O. Ajayi, and A. Arije, "Case finding for hypertension in young adult patients attending a missionary hospital in Nigeria," Afr. Health Sci., vol. 9, pp. 193-199, 2009.

[25] I. I. Ulasi, C. K. Ijoma, B. J. Onwubere, E. Arodiwe, O. Onodugo, and C. Okafor, "High prevalence and low awareness of hypertension in a market population in Enugu, Nigeria," Int. J. Hypertens., 869675, 2011, doi:10.4061/2011/869675.

[26] D. Adeloye, C. Basquill, A. V. Aderemi, J. Y. Thompson, F. A. Obi. "An estimate of the prevalence of hypertension in Nigeria: a systematic review and meta-analysis," J. Hypertens., vol. 33, pp. 230-242, 2015.

[27] M. Bello, "Nigerians wake up to high blood pressure," Bull. World Health Organ., vol. 91, pp. 242-243, 2013.

[28] J. T. Akinlua, R. Meakin, A. M. Umar, and N. Freemantle, "Current Prevalence Pattern of Hypertension in Nigeria: A Systematic Review," PloS one, vol. 10, e0140021, 2015. doi:10.1371/journal.pone.0140021.

[29] I. I. Chukwuonye, A. Chuku, C. John, K. A. Ohagwu, M. E. Imoh, S. Ejiji, et al. "Prevalence of overweight and obesity in adult Nigerians - a systematic review," Diabetes Metab. Syndr. Obes., vol. 6, pp. 43-47, 2013.

[30] J. Baalwa, B. B. Byarugaba, E. K. Kabagambe, and A. M. Otim, "Prevalence of overweight and obesity in young adults in Uganda," Afr. Health Sci., vol. 10, pp. 367-373, 2010.

[31] O. Ogunlade, and M. A. Asafa, "Pattern and Prevalence of Underweight, Overweight and Obesity Among Young Adult Nigerians," Am. J. Biomed. Life Sci., vol. 3, pp. 12-15, 2015.

[32] S. N. Akarolo-Anthony, W. C. Willett, D. Spiegelman, and C. A. Adebamowo, "Obesity epidemic has emerged among Nigerians," BMC Public Health, vol. 14: 455, 2014. https://doi.org/10.1186/1471-2458-14-455.

[33] N. Cameron, and B. Getz, "Sex differences in the prevalence of obesity in rural African adolescents," Int. J. Obes. Relat. Metab. Disord., vol. 21, pp. 775-782, 1997.

[34] A. B. Wisniewski, and S. D. Chernausek, "Gender in childhood obesity: family environment, hormones, and genes," Gend. Med., vol. 6, pp. 76-85, 2009.

[35] S. Klein, D. B. Allison, S. B. Heymsfield, D. E. Kelley, R. L. Leibel, and C. Nonas, et al. "Waist Circumference and Cardiometabolic Risk," Diabetes Care, vol. 30, pp. 1647-1652, 2007. doi: 10.2337/dc07-9921.

[36] C. Maffeis, A. Pietrobelli, A. Grezzani, S. Provera, and L. Tatò, "Waist Circumference and Cardiovascular Risk Factors in Prepubertal Children,” Obes. Res., vol. 9, pp. 179-187, 2001. doi:10.1038/oby.2001.19. 
[37] T. S. Han, E. M. van Leer, J. C. Seidell, and M. E. Lean, "Waist circumference action levels in the identification of cardiovascular risk factors: prevalence study in a random sample," BMJ, vol. 311, pp. 1401-1405, 1995. doi:10.1136/bmj.311.7017.1401.

[38] J. Stevens, E. G. Katz, and R. R. Huxley, "Associations between gender, age and waist circumference,” Eur. J. Clin. Nutr., vol. 64, pp. 6-15, 2010.

[39] World Health Organization. "Waist circumference and waist-hip ratio: report of a WHO expert consultation," Geneva, 8-11 December 2008, 2011.

[40] U. Agu, M. C. Agu, and G. A. Nnaji, "Assessment of risk of developing diabetes mellitus among local government employees in Onitsha, south-eastern Nigeria," Epidemiol. Rep., vol. 3: 4, 2015.

[41] L. T. Mitolo, W. N. Dare, and L. E. Chris-Ozoko, "Body Mass Index (BMI) and Waist Hip Ratio (WHR) Among Young Adults of Delta State Origin," World J. Med. Sci., vol. 12, pp. 21-25, 2015.

[42] O. Adegbija, W. Hoy, and Z. Wang, "Prediction of cardiovascular disease risk using waist circumference among Aboriginals in a remote Australian community," BMC Public Health, vol. 15: 57, 2015. doi:10.1186/s12889-015-1406-1.

[43] S. A. E. Peters, S. H. Bots, and M. Woodward, "Measures of General and Central Adiposity and the Risk of Myocardial Infarction: Results From the UK Biobank," J. Am. Heart Assoc., vol. 7: e008507, 2018.

[44] O. C. Oguejiofor, C. H. Onwukwe, and C. U. Odenigbo, "Dyslipidemia in Nigeria: prevalence and pattern," Ann. Afr. Med., vol. 11, pp. 197-202, 2012. doi: 10.4103/1596-3519.102846.

[45] D. B. Ojji, S. O. Ajayi, M. H. Mamven, and J. Atherton, "Prevalence of dyslipidemia in normoglycemic subjects with newly diagnosed high blood pressure in Abuja, Nigeria," J. Clin. Lipidol., vol. 3, pp. 51-56, 2009.

[46] H-W, Breuer, "Low Density Lipoprotein Cholesterol And Coronary Heart Disease - Lower Is Better," European Cardiology, vol. 1, pp. $1-6,2005$.

[47] M. A. Olamoyegun, R. Oluyombo, and S. O. Asaolu, "Evaluation of dyslipidemia, lipid ratios, and atherogenic index as cardiovascular risk factors among semi-urban dwellers in Nigeria," Ann. Afr. Med., vol. 15, pp. 194-199, 2016. doi:10.4103/1596-3519.194280.

[48] S. Niroumand, M. Khajedaluee, M. Khadem-Rezaiyan, M. Abrishami, M. Juya, G. Khodaee, et al. "Atherogenic Index of Plasma (AIP): A marker of cardiovascular disease,” Med. J. Islam Repub. Iran, vol. 29: 240, 2015.

[49] T. T. Wu, Y. Gao, Y. Y. Zheng, Y. T. Ma, and X. Xie, "Atherogenic index of plasma (AIP): a novel predictive indicator for the coronary artery disease in postmenopausal women," Lipids Health Dis., vol. 17: 197, 2018. doi:10.1186/s12944-018-0828-z.

[50] M. S. Bo, W. L. Cheah, S. Lwin, T. M. Nwe, T. T. Win, and M. Aung, "Understanding the Relationship between Atherogenic Index of Plasma and Cardiovascular Disease Risk Factors among Staff of a University in Malaysia," J. Nutr. Metab., 7027624, 2018. https://doi.org/10.1155/2018/7027624.
[51] M. C. Cure, A. Tufekci, E. Cure, S. Kirbas, S. Ogullar, A. Kirbas, et al. "Low-density lipoprotein subfraction, carotid artery intima-media thickness, nitric oxide, and tumor necrosis factor alpha are associated with newly diagnosed ischemic stroke," Ann. Indian Acad. Neurol., vol. 16, pp. 498-503, 2013.

[52] H. C. Gerstein, K. Swedberg, J. Carlsson, J. J. McMurray, E. L. Michelson, B. Olofsson, et al. "The hemoglobin A1c level as a progressive risk factor for cardiovascular death, hospitalization for heart failure, or death in patients with chronic heart failure: an analysis of the Candesartan in Heart failure: Assessment of Reduction in Mortality and Morbidity (CHARM) program," Arch. Intern. Med., vol. 168, pp. 1699-1704, 2008.

[53] E. Selvin, M. W. Steffes, H. Zhu, K. Matsushita, L. Wagenknecht, J. Pankow, et al. "Glycated hemoglobin, diabetes, and cardiovascular risk in nondiabetic adults," N. Engl. J. Med., vol. 362, pp. 800-811, 2010. doi:10.1056/NEJMoa0908359.

[54] S. L. A. Yeung, L. Luo, and C. M. Schooling, "The Impact of Glycated Hemoglobin (HbA1c) on Cardiovascular Disease Risk: A Mendelian Randomization Study Using UK Biobank," Diabetes Care, vol. 41, pp. 1991-1997, 2018. doi: 10.2337/dc18-0289.

[55] C. Welsh, P. Welsh, C. A. Celis-Morales, P. B. Mark, D. Mackay, N. Ghouri, et al. "Glycated Hemoglobin, Prediabetes, and the Links to Cardiovascular Disease: Data From UK Biobank," Diabetes Care, 2019. doi:10.2337/dc19-1683.

[56] D. M. Capuzzi, and J. S. Freeman, "C-Reactive Protein and Cardiovascular Risk in the Metabolic Syndrome and Type 2 Diabetes: Controversy and Challenge," Clin. Diabetes, vol. 25, pp. 16-22, 2007. doi: 10.2337/diaclin.25.1.16.

[57] T. A. Pearson, G. A. Mensah, R. W. Alexander, J. L. Anderson, R. O. Cannon, M. Criqui, et al. "Markers of inflammation and cardiovascular disease: application to clinical and public health practice: A statement for healthcare professionals from the Centers for Disease Control and Prevention and the American Heart Association," Circulation, vol. 107, pp. 499-511, 2003.

[58] P. W. Wilson, M. Pencina, P. Jacques, J. Selhub, R. D'Agostino, and C. J. O'Donnell, "C-reactive protein and reclassification of cardiovascular risk in the Framingham Heart Study," Circ. Cardiovasc. Qual. Outcomes., vol. 1, pp. 92-97, 2008. doi:10.1161/CIRCOUTCOMES.108.831198.

[59] Y. Dong, X. Wang, L. Zhang, Z. Chen, C. Zheng, J. Wang, et al. "High-sensitivity $\mathrm{C}$ reactive protein and risk of cardiovascular disease in China-CVD study," J. Epidemiol. Community. Health, vol. 73, pp. 188-192, 2019.

[60] P. M. Ridker, "Clinical application of C-reactive protein for cardiovascular disease detection and prevention," Circulation, vol. 107, pp. 363-369, 2003.

[61] O. A. Adejumo, E. I. Okaka, C. G. Okwuonu, I. O. Iyawe, and O. O Odujoko, "Serum C-reactive protein levels in pre-dialysis chronic kidney disease patients in southern Nigeria," Ghana Med. J., vol. 50, pp. 31-38, 2016. doi:10.4314/gmj.v50i1.5. 